\title{
The large-scale magnetospheric electric field observed by Double Star TC-1
}

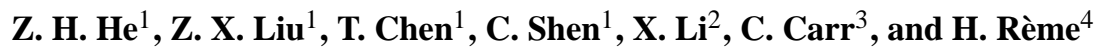 \\ ${ }^{1}$ State Key Laboratory of Space Weather, Center for Space Science and Applied Research, Chinese Academy of Sciences, \\ Beijing, China \\ ${ }^{2}$ Laboratory for Atmospheric and Space Physics, University of Colorado, Boulder, CO, USA \\ ${ }^{3}$ Space and Atmospheric Physics, the Blackett Laboratory, Imperial College, London, UK \\ ${ }^{4}$ CESR, Toulouse, France
}

Received: 22 September 2009 - Revised: 28 July 2010 - Accepted: 27 August 2010 - Published: 3 September 2010

\begin{abstract}
The relationship between the average structure of the inner magnetospheric large-scale electric field and geomagnetic activity levels has been investigated by Double Star TC-1 data for radial distances $\rho$ between $4.5 R_{\mathrm{E}}$ and $12.5 R_{\mathrm{E}}$ and MLT between 18:00 $\mathrm{h}$ and 06:00 h from July to October in 2004 and 2005. The sunward component of the electric field decreases monotonically as $\rho$ increases and approaches zero as the distance off the Earth is greater than $10 R_{\mathrm{E}}$. The dawn-dusk component is always duskward. It decreases at about $6 R_{\mathrm{E}}$ where the ring current is typically observed to be the strongest and shows strong asymmetry with respect to the magnetic local time. Surprisingly, the average electric field obtained from TC-1 for low activity is almost comparable to that observed during moderate activity, which is always duskward at the magnetotail (8 $\left.R_{\mathrm{E}} \sim 12 R_{\mathrm{E}}\right)$.
\end{abstract}

Keywords. Magnetospheric physics (Electric fields)

\section{Introduction}

The variation of the large-scale electric field near the equatorial plane of the inner magnetosphere associated with geomagnetic activity is very closely related to the physics of plasma dynamics and energy transport in the inner magnetosphere, such as plasma injection into and earthward of geosynchronous orbit and overall particle transport during geomagnetic substorms and storms (Reeves, 1998; Li et al., 1998). The electric field in the inner magnetosphere has been generally believed to consist of the dawn-dusk convection

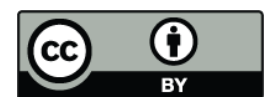

Correspondence to: Z. H. He

(he_zh@cssar.ac.cn) electric field and the corotation electric field. A number of electric potential models have been developed based on experimental data and theoretical hypotheses. One of the most widely used to study the inner magnetospheric electric field is Volland-Stern model, which includes a semiemperical convection and the pure corotation electric field (Volland, 1973; Stern, 1975; Maynard and Chen, 1975). An analytic function representing the quiet time magnetospheric electric field has been constructed based on particle drifts by McIlwain (1972). The numerous models related to the inner and midtail electric field have been developed to study the ring current asymmetry (Jordanova et al., 2006) and predict the Dst index (Liemohn et al., 2001). The Rice Convection Model including the effects of magnetoshoeric shielding, subauroral ion drifts and region- 2 currents produced by pressure gradients associated with the inner edge of the plasma sheet have been used to magnetic storm case studies (Sayzkin et al., 2000; 2002; Toffelloto et al., 2003).

Several studies based on the explorations of DMSP satellite (Yeh et al., 1991) and Akebono satellite (Shinbori et al., 2005) have shown that the large-scale strong electric field with the magnitude more than $10 \mathrm{mV} \mathrm{m}^{-1}$ is usually observed around $L=3$ during geomagnetic storms. Baumjohann et al. (1985) and Baumjohann and Haerendel (1985) have concluded that the electric field between 06:00 and 21:00 LT at certain radial position ( $L=6.6)$ scaled with both geomagnetic activity $(\mathrm{Kp})$ and the solar wind electric field. A statistical analysis on measurements from Goddard Space Flight Center electric field instrument on ISEE-1 showed that the magnitude of the electric field in the equatorial plane $(L=2.5-5.0)$ varied between 0.2 and $0.8 \mathrm{mV} \mathrm{m}^{-1}$ and exceeding $2.0 \mathrm{mV} \mathrm{m}^{-1}$ during the intense activity (Maynard et al., 1983). Furthermore, Rowland and Wygant (1998) made a

Published by Copernicus Publications on behalf of the European Geosciences Union. 
more detailed survey of the CRRES electric field in the magnetic local time sector between 12:00 and 04:00 within an Lvalue range from 2.5 to 8.5 . They found that character of the enhanced electric field can be described as a function of magnetic activity (Kp index) and the $E_{\mathrm{y}}$ component is enhanced between $L=4$ and $L=6$ in the dusk to midnight region during geomagnetically active periods of $\mathrm{Kp}>4$.0. However, the sunward component of the electric field has not been studied, and the character of the $E_{\mathrm{y}}$ component of the electric field in the dawnside has not yet been described due to lack of observations in that section. The data used in CRRES survey was about $4100 \mathrm{~h}$ while the ISSE- 1 orbital coverage in the equatorial region for one year was about $200 \mathrm{~h}$.

In this paper, the character of the large-scale electric field in the inner magnetosphere will be investigated by performing a statistical analysis on the magnetospheric electric field data obtained from the Double Star TC-1 satellite (Liu et al., 2005). There is no actual instrument that measure electric field on the TC-1, but using measured magnetic field from the FGM (Fluxgate Magnetic) instrument (Carr et al., 2005) and the ion bulk velocity obtained from the HIA (Hot Ions Analyze) instrument (Rème et al., 2005), one may construct an electric field estimate from the equation $\boldsymbol{E}=-\boldsymbol{V} \times \boldsymbol{B}$. One work has compared the $-\boldsymbol{V} \times \boldsymbol{B}$ with EDI and EFW instruments from Cluster observation, and results are good (Eriksson et al., 2006). The HIA and FGM instrument on Double Star are the same with Cluster mission. So we assume that the items of divergences of the pressure tensor, inertia effects, and resistivity in the Generalized Ohm's Law are small.

The organization of this paper is as follows. The data description is in Sect. 2. The statistical results of the sunward and dawn-dusk components including the average feature and standard deviations are presented in Sect. 3. Comparisons with previous electric field observations and the Volland-Stern electric field model are made in Sect. 4. Finally, conclusions are given in Sect. 5.

\section{Data}

The Double Star TC-1 satellite was launched on 30 December 2003 into a near-equatorial orbit (orbital inclination $28.5^{\circ}$ ), with an orbital period of $27.4 \mathrm{~h}$, an apogee of $13.4 R_{\mathrm{E}}$ and a perigee of $570 \mathrm{~km}$ (Liu et al., 2005). The spacecraft was closer to the equatorial plane during the magnetotail crossing from July through October 2004-2005, providing a great opportunity to investigate the large-scale electric field in this region. HIA and FGM take data every $4 \mathrm{~s}$.

The statistical analysis of the large-scale electric field is performed by analyzing the TC- 1 data over $2500 \mathrm{~h}$ from July to October 2004 and 2005. The Geocentric Solar Magnetospheric System (GSM) is chosen to analysis the data. We define the radial distance $\rho=\sqrt{X(\mathrm{GSM})^{2}+Y(\mathrm{GSM})^{2}}$, and all the valid data with $\rho$ parameter between $\rho=4.5$ and $\rho=12.5$ and magnetic local time (MLT) between 18:00 and 06:00 and $Z(\mathrm{GSM})$ between $-1.5 R_{\mathrm{E}}$ and $1.5 R_{\mathrm{E}}$ have been included. The corotation electric field, $\boldsymbol{E}_{\mathrm{cor}}=\frac{C / R_{\mathrm{E}}}{\left(r / R_{\mathrm{E}}\right)^{2}} \boldsymbol{e}_{r}$ and $C=92.4 \mathrm{KVR}_{E}$, has been subtracted in the data analysis. The $\rho$ parameter is used for the variable $r$ instead of the L-shell because near the earth the L-shell and $\rho$ are comparable. The error from the difference radiance distance definition is very small, about $5 \%$.

The data are divided into five Kp bins, each of them are subdivided into eight bins according to $\rho$ value with $1 R_{\mathrm{E}}$ wide. The numbers of hours of data for each bin are demonstrated in Fig. 1a. Because the satellite spends most of its orbit at large distances and the geomagnetic activity is more often quiet than active, there are about $250 \mathrm{~h}$ in the $1<\mathrm{Kp}<2,11.5<\rho<12.5$ bin, while there are less than $10 \mathrm{~h}$ in the $4<\mathrm{Kp}<5,5.5<\rho<6.5 \mathrm{bin}$. The data are also divided into two parts: the magnetic quiet time $\mathrm{Kp}$ between 0 and 3and moderate activity time for Kp between 3 and 5-, each of them are subdivided into eight bins according to $\rho$ value with $1 R_{\mathrm{E}}$ wide, and each $\rho$ bin are subdivided into twelve bins according to magnetic local time with $1 \mathrm{~h}$ wide from 18:00 to 06:00. Figure $1 \mathrm{~b}$ and $\mathrm{c}$ shows the number of hours of data for each bin. The data obtained by TC-1 during the high geomagnetic activity, $\mathrm{Kp}>6$, are not discussed in this paper because there is not enough data set to reach the reasonable conclusions.

\section{Observational results}

Figure 2a represents the variations of the sunward component $\left(E_{\mathrm{x}}\right)$ of electric field as a function of $\rho$ and $\mathrm{Kp}$ index. Five colored curves denote the geomagnetic activity levels from 0 to $5-$ as mentioned in Sect. 2. Each data point is plotted in the center of the corresponding $\rho$ bin from which the data were obtained. Error bars corresponding to the variance of the mean are plotted along with each point. The data indicate that the $E_{\mathrm{x}}$ component decreases monotonically in magnitude from $0.7 \mathrm{mV} \mathrm{m}^{-1}$ to about $0 \mathrm{mV} \mathrm{m}^{-1}$ as $\rho$ increases from 4.5 to 12.5 . It approaches zero as the distance off the Earth is greater than $10 R_{\mathrm{E}}$.

Figure $2 \mathrm{~b}$ presents the $E_{\mathrm{X}}$ component varies with the different magnetic local time (MLT) between 18:00 and 05:00 for low activity $(0 \leq K p<3)$ and Fig. $2 c$ contains data for moderate activity $(3 \leq \mathrm{Kp}<5)$. The eight colored curves represent the eight different $\rho$ values from 5 to 12 . For $0 \leq \mathrm{Kp}<3$, the $E_{\mathrm{x}}$ component is sunward and has gently increased from about $0 \mathrm{mV} \mathrm{m}^{-1}$ to $0.5 \mathrm{mV} \mathrm{m}^{-1}$ for MLT from 23:00 to 05:00 and deeply decreased from over $1.0 \mathrm{mV} \mathrm{m}^{-1}$ to about $0 \mathrm{mV} \mathrm{m}^{-1}$ for MLT between 18:00 and 21:00 for low activity except for the region between 21:00 to 23:00, in which its direction is anti-sunward. For moderate activity, the region with anti-sunward velocity has disappeared. The average magnitudes of the $E_{\mathrm{x}}$ components near the duskside 


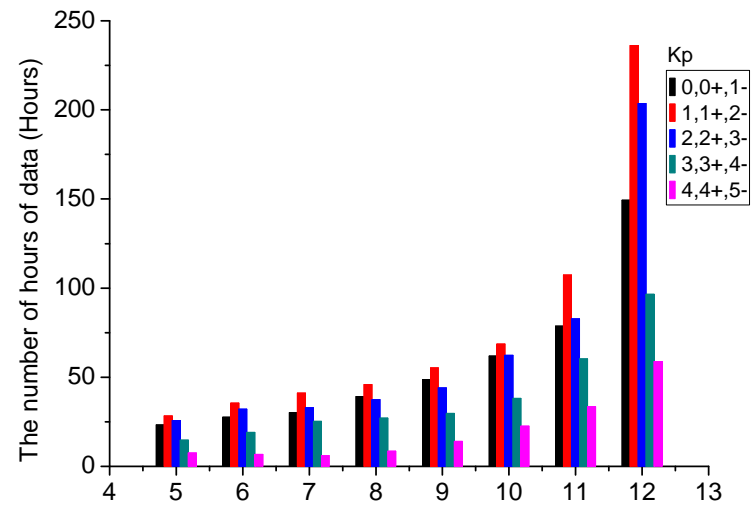

(a)

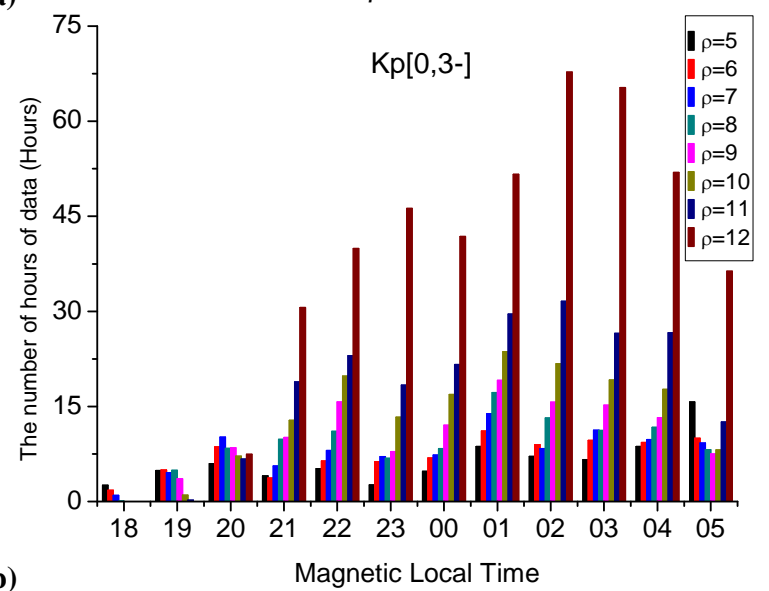

(b)

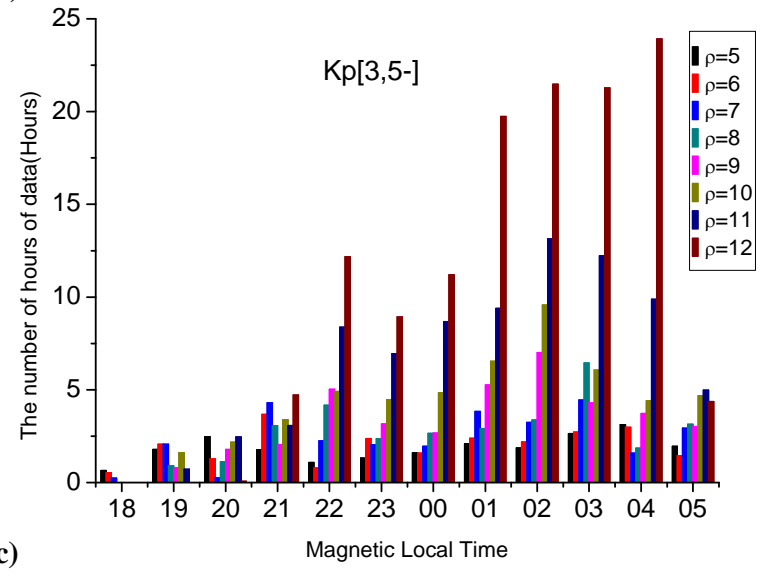

Fig. 1. (a) The number of hours of data in each $\rho$ bin for five different Kp bins. (b) The number of hours of data in each magnetic local time bin for eight different $\rho$ bins at magnetic quiet time $\mathrm{Kp}[0,3-]$. (c) The number of hours of data in each magnetic local time bin for eight different $\rho$ bins at magnetic moderate activity time $\mathrm{Kp}[3,5-]$.

are much greater than that near the dawnside for both low and moderate activity.

Figure 3a shows the variations of the dawn-dusk component $\left(E_{\mathrm{y}}\right)$ of the electric field as a function of $\rho$ and $\mathrm{Kp}$ index. The data indicate that the $E_{\mathrm{y}}$ component is always duskward over the magnetic local time range from 18:00 to

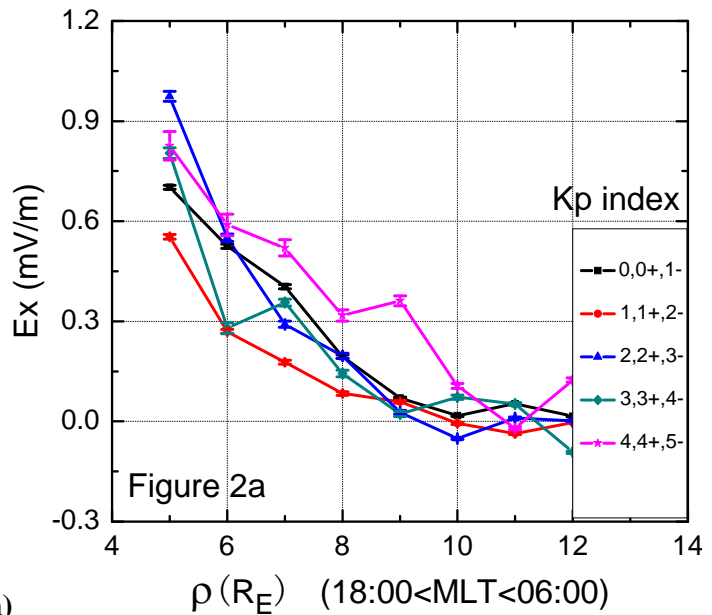

(a)

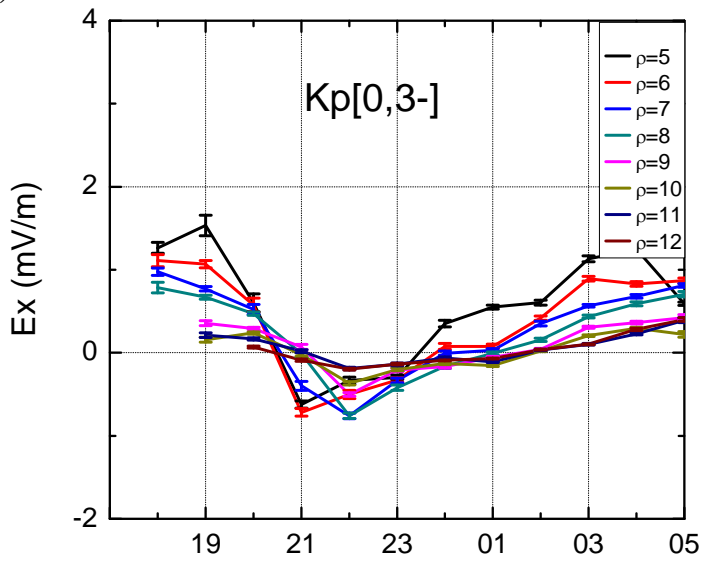

(b)

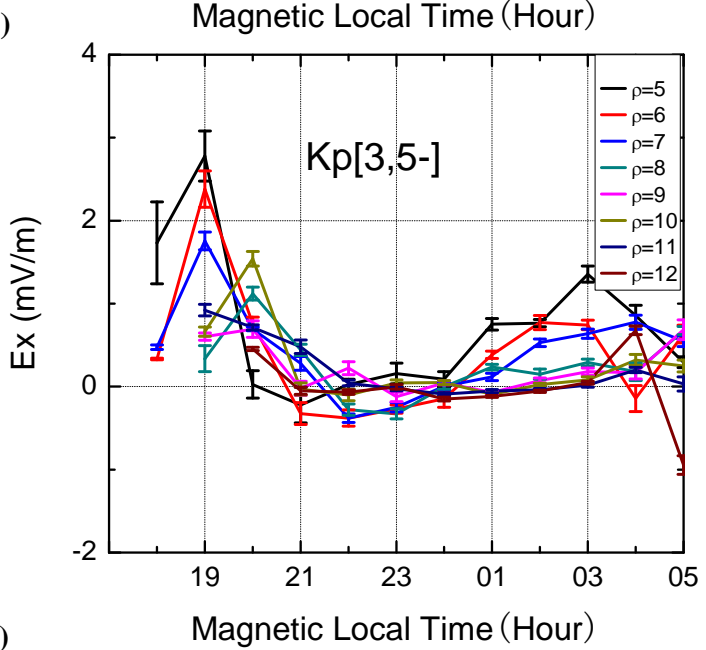

Fig. 2. (a) The variation of the $E_{\mathrm{X}}$ component of the electric field as a function of $\rho$ value and geomagnetic activity $\mathrm{Kp}$ index. (b) The variation of the $E_{\mathrm{X}}$ component of the electric field as a function of magnetic local time for geomagnetic activity Kp less than 3. (c) The variation of the $E_{\mathrm{X}}$ component of the electric field as a function of magnetic local time for geomagnetic activity Kp between 3 and 5-. 


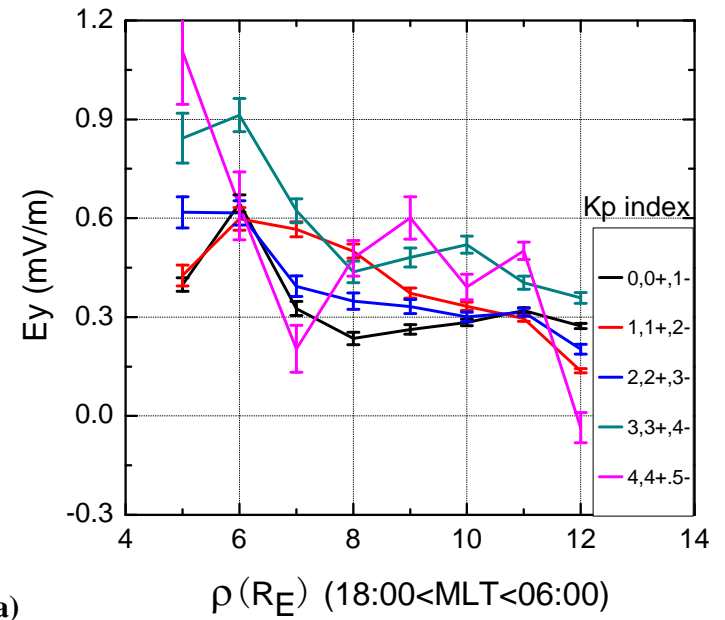

(a)

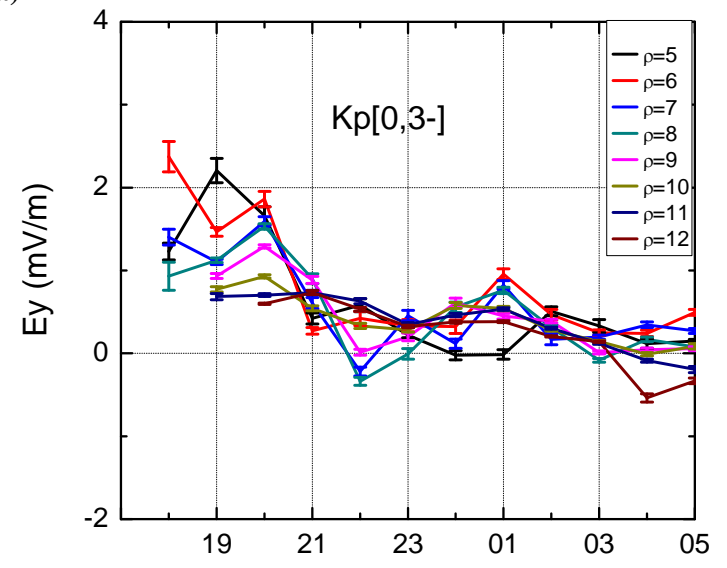

(b)

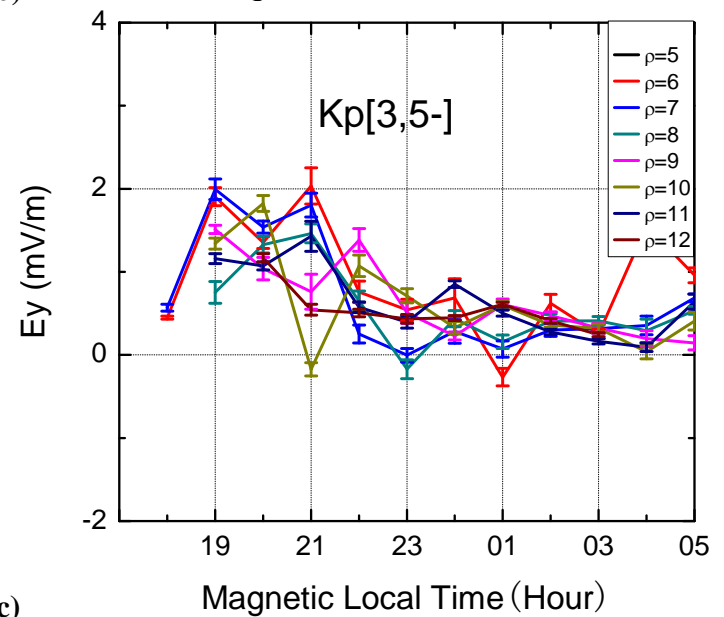

Fig. 3. (a) The variation of the dawn-dusk component of the electric field as a function of $\rho$ value and geomagnetic activity Kp index. (b) The variation of the $E_{\mathrm{y}}$ component of the electric field as a function of magnetic local time for geomagnetic activity Kp less than 3 . (c) The variation of the $E_{\mathrm{y}}$ component of the electric field as a function of magnetic local time for geomagnetic activity Kp between 3 and $5-$.

Ann. Geophys., 28, 1625-1631, 2010
06:00, in a manner consistent with $\boldsymbol{E} \times \boldsymbol{B}$ convection from tail toward the dayside, and is generally stronger for higher Kp. These results are supported by the early balloon measurements (Mozer and Lucht, 1974), ISSE 1 observations (Maynard et al., 1983) and CRRES (Wygant et al., 1997).

The error bars in Figs. 2 and 3 are represented the variances of the mean of the data rather than the standard deviations. Generally, these variances are small except for moderate activity levels and low $\rho$ values. The variance of the mean describes the variability of the average electric field in a given $\rho$ value-Kp bin from the average. The standard deviation of a single point from the mean is larger than the mean value of the electric field in a given $\rho$ value and $\mathrm{Kp}$ bin, indicating the highly variable nature of the electric field in this region. The error bars in this paper are comparable to the one with Rowland and Wygant's work (1998).

The inner edge of the plasma sheet tends to shield the inner magnetosphere from the main electric convection field. If the convection field suddenly decrease, due to a northward turning of the IMF, there is suddenly a backwards electric field (dusk to dawn) in the inner magnetosphere temporarily, until the shielding layer readjusts. This is called overshielding. Undershielding is temporarily penetration of dawn-dusk electric field in times of increasing convection (Sayzkin et al., 2000). The most striking feature of the $E_{\mathrm{y}}$ component is the peak value at $\rho=6$, which separate two trends that $E_{\mathrm{y}}$ component changes with the $\rho$. The dawn-dusk component increases with the $\rho$ increasing when the $\rho$ is less than 6 , while the total oppositional trend is observed for $\rho$ between 6 and 8. The inner edge of the plasma sheet is located at $\rho=6$, and it may move earthward for $\mathrm{Kp}>4$. The TC-1 observation shows undershielding effect in the inner magnetosphere because average dawn-dusk electric field is positive for $\rho$ less than 6 . When $\rho$ between 8 and 12, the dawn-dusk component of electric field reaches $0.5 \mathrm{mV} \mathrm{m}^{-1}$ for $\mathrm{Kp} \geq 3$, while maintains about $0.3 \mathrm{mV} \mathrm{m}^{-1}$ for $\mathrm{Kp}<3$. It is well known that the $E_{\mathrm{y}}$ component of Volland-Stern electric field always increases with the radial distance. It is contradictory to the results of this paper and also is not consistent with the Wygant et al. (1997) work, especially for the geomagnetic storm time.

It should be noticed that the convection electric field changes with the different magnetic local time from 18:00 to 05:00 for low (Fig. 3b) and moderate activity (Fig. 3c). The $E_{\mathrm{y}}$ component varies between $0 \mathrm{mV} \mathrm{m}^{-1}$ and about $0.5 \mathrm{mV} \mathrm{m}^{-1}$ from MLT=23:00 to MLT=05:00 for both low and moderate activity. For the magnetic local time between 18:00 and 23:00, the magnitude for moderate activity strengthens slighter than the low one.

Figure $4 \mathrm{a}$ and $\mathrm{b}$ demonstrates the electric field vector in equatorial plane for low and moderate geomagnetic activity separately. Figure $4 \mathrm{a}$ shows that the electric field in the dawnside always points to sunward direction with the magnitude about $0.3 \mathrm{mV} \mathrm{m}^{-1}$, while it turns rather turbulent when the geomagnetic activity is moderate. Near the duskside, the magnitude of the electric field is above $1.5 \mathrm{mV} \mathrm{m}^{-1}$ for low 
activity, and it becomes much greater for moderate activity; the angle between electric field vector and the dawn-dusk meridian is mainly less than 40 degrees. It is surprising that in the magnetotail between $9 R_{\mathrm{E}}$ and $12 R_{\mathrm{E}}\left(|Y \mathrm{GSM}|<5 R_{\mathrm{E}}\right)$, the electric field which almost appears duskward with magnitude about $0.3 \mathrm{mV} \mathrm{m}^{-1}$ for moderate activity is comparable to that for low activity.

\section{Discussion}

This paper has studied the large-scale electric field in the inner and middle magnetosphere as a function of geomagnetic activity. Observations from Akebono/EFD have indicated that the $E_{\mathrm{x}}$ component fairly coincides with the corotation electric field in the quiet time (Nishimura et al., 2006), while the statistical results by TC- 1 data show that even for the lowest geomagnetic activity level $(\mathrm{Kp}<1)$ there should be some other electric field source, which contributes to the sunward component of the electric field except for the corotaion electric field. The structure of the electric field from Akebono/EFD shows a strong asymmetry with respect to the noon-midnight meridian as well as the dawn-dusk meridian; TC-1 observation indicates a strong asymmetry with respect to the magnetic local time that the electric field at duskside is at least three times more than the one at dawnside.

Several modeling studies of the storm-time ring current (Chen et al., 1993; Fok et al., 1996; Sazykin et al., 2002; Liemohn et al., 2001; Wang et al., 2004) suggest that an enhanced convection electric field in the magnetosphere, which is induced by a continuous southward interplanetary magnetic field (IMF), is responsible for steady particle transport into the inner magnetosphere during the storm main phase. The enhanced convection is envisioned to be weakened, or cease after the main phase in response to the decrease of southward IMF, leading to the formation of a relatively symmetric ring current around the Earth during the recovery phase. Surprisingly, in the magnetotail between $9 R_{\mathrm{E}}$ and $12 R_{\mathrm{E}}\left(|Y \mathrm{GSM}|<5 R_{\mathrm{E}}\right)$, the electric field almost appears duskward with magnitude about $0.3 \mathrm{mV} \mathrm{m}^{-1}$ for moderate activity is comparable to that for low activity. Fortunately, that is supported by a Geotail spacecraft investigation during storm time, which found that during both the main and recovery phases the electric field was relatively steady and weak with average magnitude about $0.3 \mathrm{mV} \mathrm{m}^{-1}$, and was almost comparable to that observed during the quiet times (Hori et al., 2005). As inferred from the bulk ion flow velocity from Shen et al. (2008), the convection is rather weak, which agrees with the TC-1 observations well.

Wygant et al. (1997) reported that the convection electric field increases with $\rho$ less than $6.0 R_{\mathrm{E}}$ for low activity, while for the higher activity the dawn-dusk electric field can penetrate deeply into the inner radiation belt. This phenomenon can also be seen from the TC- 1 observation; furthermore the shielding position identified in this work is about $6.0 R_{\mathrm{E}}$.

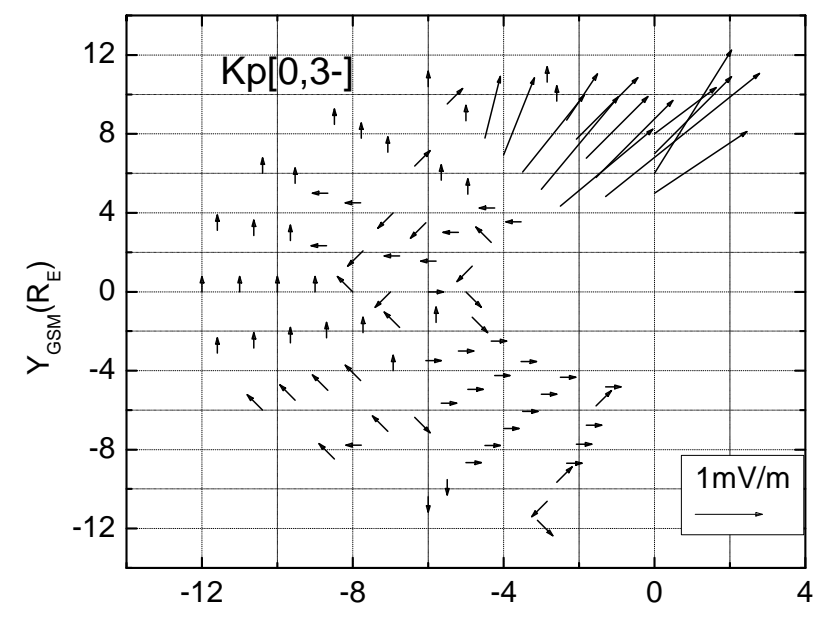

(a)

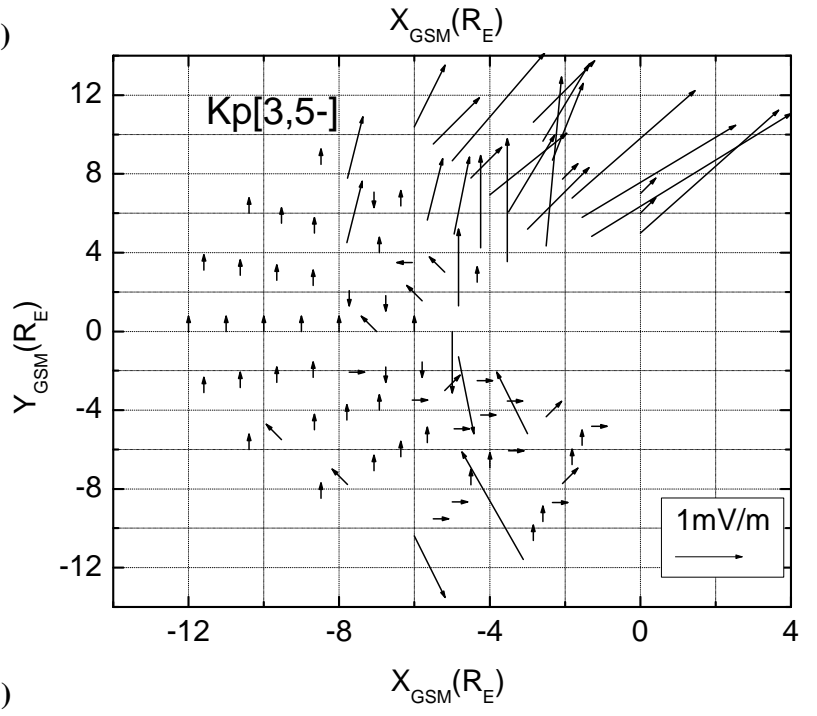

Fig. 4. (a) The electric field vector in equatorial plane for $\mathrm{Kp}$ between 0 and $3-$. (b) The electric field vector in equatorial plane for Kp between 3 and 5-.

However, the convection electric field decreases at about $6.0 R_{\mathrm{E}}$ with the increasing $\rho$, and maintains a constant at the magnetotail over about $9.0 R_{\mathrm{E}}$. This trend is completely opposite to that of the Volland-Stern electric field.

\section{Conclusion}

The relationship between the average structure of the inner magnetospheric electric field and geomagnetic activity levels is investigated by Double Star TC-1 with $\rho$ between $4.5 R_{\mathrm{E}}$ and $12.5 R_{\mathrm{E}}$ and MLT between 18:00 $\mathrm{h}$ and $05: 00 \mathrm{~h}$ from July to October in 2004 and 2005 and $Z(\mathrm{GSM})$ between $-1.5 R_{\mathrm{E}}$ and $1.5 R_{\mathrm{E}}$. The conclusions made by data analysis are as follows.

The $E_{\mathrm{x}}$ component decreases monotonically in the magnitude from $0.7 \mathrm{mV} \mathrm{m}^{-1}$ to nearly $0 \mathrm{mV} \mathrm{m}^{-1}$ as $\rho$ increases from 4.5 to 12.5 . The average dawn-dusk component $\left(E_{\mathrm{y}}\right)$ of 
the electric field is always duskward, scaling in the magnitude from $0 \mathrm{mV} \mathrm{m}^{-1}$ to $0.7 \mathrm{mV} \mathrm{m}^{-1}$ as $\mathrm{Kp}$ increasing from 0 to 5-. The structure of the electric field shows strong asymmetry with respect to the magnetic local time. The electric field at duskside is at least three times more than the one at dawnside. The shielding distance, which the electric field is shielded out of the inner magnetosphere, can be located at about $\rho=6$ and moves earthward when $\mathrm{Kp}$ is larger.

The average electric field obtained for low activity is almost comparable to that observed during moderate activity and is always duskward at the magnetotail $\left(8 R_{\mathrm{E}} \sim 12 R_{\mathrm{E}}\right)$. A revised model may be much better than the VollandStern model for interpreting the electric field at magnetotail $\left(-12 R_{\mathrm{E}} \leq R \leq-6 R_{\mathrm{E}}\right)$.

Acknowledgements. The authors would like to thank Forrest S. Mozer and another referee for evaluating this paper. This work was supported by the National Natural Science Foundation of China Grant No. 40731054, 40904044, 40774081, G2006CB806305 and the Specialized Research Fund for State Key Laboratories.

Topical Editor I. A. Daglis thanks F. S. Mozer and another anonymous referee for their help in evaluating this paper.

\section{References}

Baumjohann, W., Haerendel, G., and Melzner, F.: Magnetospheric convection observed between 0600 and 2100 LT: Variations with Kp, J. Geophys. Res., 90, 393-398, 1985.

Baumjohann, W. and Haerendel, G.: Magnetospheric convection observed between 0600 and 2100 LT: Solar wind and IMF dependence, J. Geophys. Res., 90, 6370-6378, 1985.

Carr, C., Brown, P., Zhang, T. L., Gloag, J., Horbury, T., Lucek, E., Magnes, W., O'Brien, H., Oddy, T., Auster, U., Austin, P., Aydogar, O., Balogh, A., Baumjohann, W., Beek, T., Eichelberger, H., Fornacon, K.-H., Georgescu, E., Glassmeier, K.-H., Ludlam, M., Nakamura, R., and Richter, I.: The Double Star magnetic field investigation: instrument design, performance and highlights of the first year's observations, Ann. Geophys., 23, 27132732, doi:10.5194/angeo-23-2713-2005, 2005.

Chen, M. W., Schulz, M., Lyon, L. R., and Gorney, D. J.: Storm time transport of ring current and radiation belt ions, J. Geophys. Res., 98, 3835-3849, 1993.

Eriksson, A. I., André, M., Klecker, B., Laakso, H., Lindqvist, P.-A., Mozer, F., Paschmann, G., Pedersen, A., Quinn, J., Torbert, R., Torkar, K., and Vaith, H.: Electric field measurements on Cluster: comparing the double-probe and electron drift techniques, Ann. Geophys., 24, 275-289, doi:10.5194/angeo-24275-2006, 2006.

Fok, M.-C., Moore, T. E., and Greenspan, M. E.: Ring current development during storm main phase, J. Geophys. Res., 101, 15311-15322, 1996.

Hori, T., Lui A. T. Y., Ohtani, S., Cson Brandt, P., Mauk, B. H., McEntire, R. W., Maezawa, K., Mukai, T., Kasaba, Y., and Hayakawa, H.: Storm-time convection electric field in the near-Earth plasma sheet, J. Geophys. Res., 110, a04213, doi:10.1029/2004ja010449, 2005.
Jordanova, V. K., Miyoshi, Y. S., Zaharia, S., Thomsen, M. F., Reeves, G. D., Evans, D. S., Mouikis, C. G., and Fennell, J. F.: Kinetic simulations of ring current evolution during the Geospace Environment Modeling challenge events, J. Geophys. Res., 111, A11S10, doi:10.1029/2006JA011644, 2006.

Li, X., Baker, D. N., Temerin, M., Reeves, G. D., and Belian, R. D.: Simulation of dispersionless injections and drift echoes of energetic electrons associated with substorms, Geophys. Res. Lett., 25(20), 3763-3766, doi:10.1029/1998GL900001, 1998.

Liemohn, M. W., Kozyra, J. U., Thomsen, M. F., Roeder, J. L., Lu, G., Borovsky, J. E., and Cayton, T. E.: Dominant role of the asymmetric ring current in producing the stormtime Dst, J. Geophys. Res., 106, 10883-10904, 2001.

Liu, Z. X., Escoubet, C. P, Pu, Z., Laakso, H., Shi, J. K., Shen, C., and Hapgood, M.: The Double Star mission, Ann. Geophys., 23, 2707-2712, doi:10.5194/angeo-23-2707-2005, 2005.

Maynard, N. C. and Chen, A. J.: Isolated cold plasma regions: Observations and their relation to possible production mechanisms, J. Geophys. Res., 80, 1009-1013, 1975.

Maynard, N. C., Aggson, T. L., and Heppner, J. P.: The plasmaspheric electric field as measured by ISEE 1, J. Geophys. Res., 88, 3991-4003, 1983.

McIlwain, C. E.: in: Earth's Magnetospheric Processes, edited by: McCormac, B. M., D. Reidel, Dordrecht-Holland, p. 268, 1972.

Mozer, F. S. and Lucht, P.: The average auroral zone electric field, J. Geophys. Res., 79, 1001-1006, 1974.

Nishimura, Y., Shinbori, A., Ono, T., Iizima, M., and $\mathrm{Ku}-$ mamoto, A.: Storm-time electric field distribution in the inner magnetosphere, Geophys. Res. Lett., 33, L22102, doi:10.1029/2006GL027510, 2006.

Reeves, G. D.: New perspectives on substorm injections, Proceedings of the Fourth International Conference on Substorms, ICS-4, Hamanako, Japan, March 1998.

Rème, H., Dandouras, I., Aoustin, C., Bosqued, J. M., Sauvaud, J. A., Vallat, C., Escoubet, P., Cao, J. B., Shi, J., BavassanoCattaneo, M. B., Parks, G. K., Carlson, C. W., Pu, Z., Klecker, B., Moebius, E., Kistler, L., Korth, A., Lundin, R., and the HIA team: The HIA instrument on board the Tan Ce 1 Double Star near-equatorial spacecraft and its first results, Ann. Geophys., 23, 2757-2774, doi:10.5194/angeo-23-2757-2005, 2005.

Rowland, D. E. and Wygant, J. R.: Dependence of the large-scale, inner magnetospheric electric field on geomagnetic activity, J. Geophys. Res., 103, 14959-14964, 1998.

Sazykin, S.: Theoretical Studies of Penetration of Magnetospheric Electric Fields to the Ionosphere, PhD Dissertation, University of Utah, 2000.

Sazykin, S., Wolf, R. A., Spiro, R. W., Gombosi, T. I., De Zeeuw, D. L., and Thomsen, M. F.: Interchange instability in the inner magnetosphere associated with geosynchronous particle flux decreases, Geophys. Res. Lett., 29(10), 1448, doi:10.1029/2001GL014416, 2002.

Shen, C., Liu, Z. X., Escoubet, C. P., et al.: Surveys on magnetospheric plasmas based by the Double Star Project (DSP) exploration, Science in China Series E: Technological Sciences, 51(10), 1-9, 2008.

Shinbori, A., Nishimura, Y., Ono, T., Iizima, M., Kumamoto, A., and Oya, H.: Electrodynamics in the duskside inner magnetosphere and plasmasphere during a super magnetic storm on March 13- 15, Earth Planets Space, 57, 643-659, 2005. 
Stern, D. P.: The motion of a proton in the equatorial magnetosphere, J. Geophys. Res., 80, 595-599, 1975.

Toffoletto, F., Sazykin, S., Spiro, R., and Wolf, R.: Inner magnetospheric modeling with the Rice Convection Model, Space Sci. Rev., 107, 175-196, 2003.

Volland, H.: A semi empirical model of large-scale magnetospheric electric fields, J. Geophys. Res., 78, 171-180, 1973.

Wang, C.-P., Lyons, L. R., Chen, M. W., and Toffoletto, F. R.: Modeling the transition of the inner plasma sheet from weak to enhanced convection, J. Geophys. Res., 109, A12202, doi:10.1029/2004JA010591, 2004.
Wygant, J., Rowland, D., Singer, H. J., Temerin, M., Mozer, F., and Hudson, M. K.: Experimental evidence on the role of the large spatial scale electric field in creating the ring current, J. Geophys. Res., 103, 29527-29544, 1998.

Yeh, H.-C., Foster, J. C., Rich, F. J., and Swider, W.: Storm time electric gield penetration observed at mid-latitude, J. Geophys. Res., 96, 5707-5721, 1991. 